\title{
COST EFFECTIVENESS OF OPEN ACCESS PUBLICATIONS
}

\author{
JEVIN D. WEST, THEODORE BERGSTROM and CARL T. BERGSTROM*
}

\begin{abstract}
Open access publishing has been proposed as one possible solution to the serials crisis - the rapidly growing subscription prices in scholarly journal publishing. However, open access publishing can present economic pitfalls as well, such as excessive article processing charges. We discuss the decision that an author faces when choosing to submit to an open access journal. We develop an interactive tool to help authors compare among alternative open access venues and thereby get the most for their article processing charges. (JEL I2, C1, A1)
\end{abstract}

\section{INTRODUCTION}

Institutional subscription prices of academic journals continue to increase more rapidly than library budgets (Kyrillidou 2012). Journals produced by for-profit publishers typically cost libraries about three times as much as comparable journals produced by nonprofit publishers (Bergstrom and Bergstrom 2004a, 2006; Bergstrom and McAfee 2013). As a result, library budgets are badly strained while for-profit publishers are able to extract large profits from the university community. Open access publishing has been widely heralded as a potential solution to this so-called "serials crisis" (Willinsky 2009; Young 2009; Suber 2014).

But open access publishing is no panacea. Firstly, while author-pay open access continues to grow (Björk et al. 2010; Laakso et al. 2011), it is unclear that open access publishing will quickly - or ever - come to dominate the market for scholarly publishing (McCabe and Snyder 2010; Shieber 2009). Second, the

*The authors are the founders of the Eigenfactor Project. The open access cost effectiveness tools described here are freely available at http://www.eigenfactor.org/openaccess/. This work was supported in part by National Science Foundation Grant SBE-0915005 to C.T.B.

West: Assistant Professor, Information School, University of Washington, Seattle, WA 98195. Phone (206) 543-2646, Fax (206) 616-3152, E-mail jevinw@uw.edu

Bergstrom, T.: Professor, Department of Economics, University of California, Santa Barbara, CA 93106. Phone (805) 893-3744, Fax (805) 893-8830, E-mail tedb@econ.ucsb.edu

Bergstrom, C. T.: Professor, Department of Biology, University of Washington, Seattle, WA 98195. Phone (206) 6853487, Fax (206) 543-3041, E-mail cbergst@uw.edu author-pay model is not without its own pricing perils. Some commercial publishers levy article processing charges as high as $\$ 3,000$ for publishing a single article. A number of "predatory" open access publishers operate like vanity presses, charging authors substantial fees in exchange for the thinnest veneer of editorial oversight (Beall 2012; 2014).

On the positive side, the structure of the market for open access publications offers the potential for a more competitive marketplace than that for subscription-based publication (Bergstrom and Bergstrom 2004b). The reason is straightforward: authors, when deciding where to publish, can substitute one journal for another in order to get the best deal. This is not the case for libraries deciding what journals to subscribe to. Because open access publications are substitutes, authors can afford to comparison shop, seeking out only the very best deals and patronizing these exclusively. Should authors do so, publishers would be forced to compete aggressively on price, much as they have already started to compete on other factors such as time-to-publication. The result would be better deals for the academic community. Our aim of this article is to describe and deploy an online tool that makes it easy for scholarly authors to engage in this kind of comparison shopping.

\section{ABBREVIATIONS}

DOAJ: Directory of Open Access Journals

JCR: Thomson-Reuters Journal Citation Reports 


\section{THE AUTHOR'S PERSPECTIVE}

Academic journals require one or more revenue streams to cover their costs. There are three basic sources of revenue to which a publisher can turn: (1) authors, (2) readers, and (3) sponsors. Publishers regularly employ each of these sources, sometimes in combination. For example, Proceedings of the National Academy of Sciences of the United States of America requires authors to pay page charges, and also charges subscription fees to university libraries. The PLoS family of journals imposes article processing charges, and has received grant funding from agencies including the Sloan foundation and the MacArthur foundation. Authors may be charged upon publication of their work, upon article submission, or some combination of these. Here we examine authors' motivations for paying such fees.

The competitive peer review system used by the majority of scholarly periodicals serves to certify the novelty, interest, and quality of academic publications. Publication in a leading journal confers substantial prestige upon a scholarly author, and authors are strongly motivated by this incentive (Attema, Brouwer, and Van Exel 2014). A record of publication in the top tiers of the journal hierarchy has a critical impact on hiring, promotion, tenure, merit, salary, and funding decisions. Moreover, to have a significant influence on scholarly thought, one needs to be read widely by one's peers. Journals vary considerably in readership; researchers often conscientiously follow the publications in top journals, while turning to lower-tier journals only in pursuit of specific references. Of course prestige and readership are not independent of one another. Journals become prestigious in part because they are highly read, and prestigious journals are highly read in part because their prestige allows them to attract the top papers in a field.

When an author (or more commonly, her funders or home institution [Dallmeier-Tiessen et al. 2011]) pays open access article processing charges, she is not only paying for the broad accessibility to readers that results from open access publishing. She is also paying for the prestige and the readership that she will gain by publishing in that particular journal. When choosing among alternative venues, a sensible author would like to get as much as possible for her money. In order to quantify what an author receives in exchange for her article processing charges, we note that both prestige and

\section{FIGURE 1}

Comparing Journals

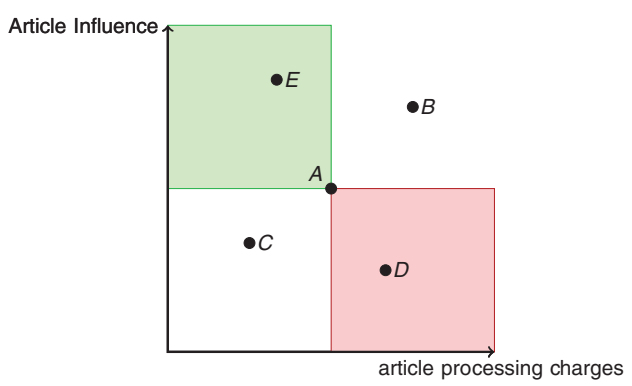

Notes: With all else equal, authors will prefer journals with higher Article Influence scores to lower, and they will prefer journals with lower article processing charges to higher. Thus an author will prefer journal A to the more expensive and less prestigious journal $\mathrm{D}$ and likewise to any journal in the red quadrant. Similarly, the author would prefer the less expensive and more prestigious journal $\mathrm{E}$ and likewise any journal in the green quadrant to journal A. How journal A compares with journals $\mathrm{B}$ and $\mathrm{C}$ depend on the author's willingness to pay extra article processing charges in exchange for extra prestige.

readership translate into the number of scholarly citations that a article receives. With all of the usual caveats (Seglen 1997), we estimate this quantity using journal-level citation data. We use the Article Influence ${ }^{\circledR}$ score $^{1}$ - a measure of per-article citations weighted by influence (West, Bergstrom, and Bergstrom 2010) - to estimate the prestige and readership obtained from publishing in a given venue. ${ }^{2}$

Figure 1 compares the deals offered by five different hypothetical journals. All else equal, authors will prefer to publish in journals with higher Article Influence scores, and with lower article processing charges.

To facilitate comparisons of this sort, we have deployed an interactive visualization that shows

1. A journal's Article Influence score is a measure of journal prestige analogous to the Impact Factor. A journal's Article Influence is calculated as a journal's Eigenfactor score, divided by the number of papers published. The journal's Eigenfactor score, described in detail by West et al. (2010), is a type of eigenvector centrality measure for the citation network in which journals represent nodes and citations represent directed links.

2. Journals provide a different type of value to authors than they do to institutional subscribers. In exchange for article processing charges, an author buys the right to publish a single article in a journal, whereas in exchange for subscription fees, a librarian buys the right to carry all articles published in the journal. Thus we use a per-article measure (Article Influence score) to quantify value to an author, whereas elsewhere (http://www.eigenfactor.org/costeffectiveness.php) we have used a per volume measure (Eigenfactor score) to quantify value to a subscriber. 


\section{FIGURE 2}

A Screenshot of the Interactive Visualization, which Can Be Found at http://www.eigenfactor.org/openaccess/

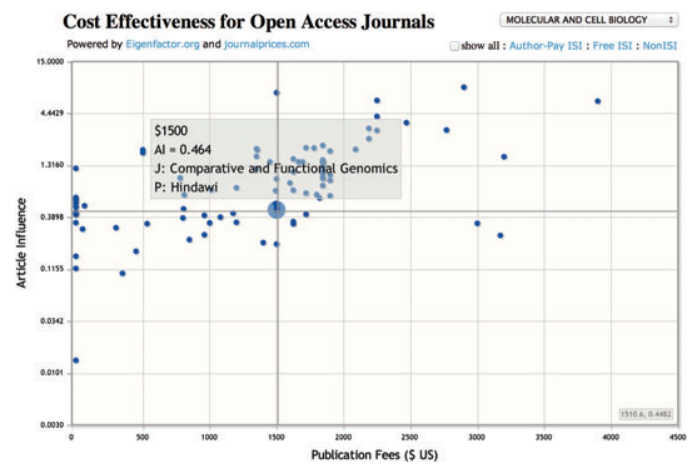

Notes: The Article Influence scores are log (base 10) transformed. The selected journal is highlighted with a larger blue circle. The "crosshairs" indicate the four quadrants noted in Figure 1.

how each open access journal compares with its competitors with regard to (1) article processing charges and (2) Article Influence score. The visualization, available at http://www.eigen factor.org/openaccess/, is shown in Figure 2.

The visualization allows users to examine articles from one discipline at a time. Disciplines are determined using the Eigenfactor Categories provided at Eigenfactor.org. These categories are derived from the community structure of the journal-level citation network, using the map equation approach (Rosvall and Bergstrom 2008). This divides the set of open access journals into 50 distinct disciplines of science and social science such that each journal belongs to a single discipline. Since these disciplinary categories are relatively wide, not all journals in a given discipline would be an appropriate venue for the same article. Journals on cardiovascular disease, epidemiology, pediatrics, and nutrition are all classified under Medicine, for example. Furthermore, many regional journals may be appropriate for only certain authors and articles. Nonetheless, the categories tend to group similarly situated journals together and as such provide a good indication of where a given journal stands relative to other open access journals on related subject matter.

Our focus here is on journals that are truly open access in that all of their content is open access. Many other journals offer hybrid open access programs in which individual articles can be made open access for a fee, often in the range of $\$$ (Pinfield 2010). It is more difficult to quantify the value of making one's article open access in a hybrid journal. On one hand, the prestige conferred by the journal is approximately the same whether one chooses to make one's article open, or not. On the other, open access articles in hybrid journals will probably attract more readers and possibly additional citations (see Wagner 2010 for an overview of the controversy around open access citation advantage).

We should note that publishing in an open access journal is not the only way to make an article freely available. Most academic journals allow immediate posting of a final refereed copy of an author's article where search engines can find them on the author's own website or in a freely available institutional archive. Harnad (2007, 2010) presents a compelling case for open access self-archiving as a means of transition to open access publishing. Harnad argues that as self-archiving becomes more widely practiced, competitive pressure will force open access publishers to realize potential costsavings of open access publication and to pass these savings on in the form of lower article processing charges. The website Sherpa/Romeo (http://www.sherpa.ac.uk/romeo/) has a nearly complete list of the policies of publishers with respect to copyright and self-archiving. ${ }^{3}$ Since this option is available for a very large number of journals, authors and institutions may prefer to self-archive at zero cost rather than pay high article processing charges to publishers for open access publication.

\section{DATA AND RESULTS}

To get an overall view of well-established open access journals, we examined 1,357 open journals included in the 2011 Thomson-Reuters Journal Citation Reports (JCR). Of these, 1,024 are listed by the Directory of Open Access Journals (DOAJ) and the rest are listed by journalprices.com as freely available. By this count, approximately $13 \%$ of the journals in the JCR are freely available. These journals account for $8 \%$ of the articles and $5 \%$ of the citations received in the JCR (Table 1). Of the publishers with the

3. Sherpa distinguishes two policies, each of which allows posting of a final copy of one's articles. These are Green-Can archive pre-print and post-print or publisher's version/PDF and Blue-Can archive post-print (i.e., final draft post-refereeing) or publisher's version/PDF. 
TABLE 1

Open Access Journals, Articles, and Citations

Received in the Thomson-Reuters Journal Citation Reports 2011

\begin{tabular}{lccc}
\hline & Journals & Articles & Citations \\
\hline Open access & 1,357 & 91,937 & 142,338 \\
All journals & 10,796 & $1,116,613$ & $2,778,668$ \\
Fraction open & $12.6 \%$ & $8.2 \%$ & $5.1 \%$ \\
\hline
\end{tabular}

TABLE 2

Contribution of Five Major Publishers to JCR 2011-Listed Open Access Publishing

\begin{tabular}{lccc}
\hline & Journals & Articles & Citations \\
\hline Biomed Central & $8 \%$ & $9 \%$ & $18 \%$ \\
PLoS & $1 \%$ & $5 \%$ & $17 \%$ \\
Hindawi & $2 \%$ & $2 \%$ & $1 \%$ \\
Springer & $2 \%$ & $3 \%$ & $2 \%$ \\
Elsevier & $1 \%$ & $1 \%$ & $1 \%$ \\
\hline
\end{tabular}

largest open access portfolios-Biomed Central, PLoS, Hindawi, Springer, and Elsevier-PLoS and Biomed Central account for the vast majority of citations received (Table 2). Rather than being concentrated in one or a few countries, open access publishing is well-represented on an international scale, with 26 nations publishing more than 10 JCR-listed open access journals (Table 3 ).

Of the open access journals in our study, $71 \%$ request no article processing charges whatsoever. These journals account for about $1 / 3$ of the citations received by open access journals. Journals without processing charges are able to cover their costs in a number of different ways. It is important to realize that an efficiently run access journal can operate with very low costs. Founders and editors of three open access journals, Stuart Shieber, of the Journal of Machine Learning Research (see http:// blogs.law.harvard.edu/pamphlet/2012/03/06/anefficient-journal), Conley and Wooders (2009) of Economics Bulletin, and Caveleri et al. (2009) of the European Journal of Comparative Economics supply detailed explanations of how an open access journal can be published cheaply. From the time of its founding in 2006 until its takeover by the Econometric Society in 2010, the open access journal Theoretical Economics was able to cover all of its costs with a $\$ 75$ submission fee and no author processing charge. (See http://econtheory.org/history.php for a brief history of this journal.) Many open access journals
TABLE 3

Open Access Journals, Articles, and Citations Received by Country of Publication

\begin{tabular}{lrrr}
\hline & Journals & Articles & Citations \\
\hline United States & 164 & 14,718 & 41,581 \\
Brazil & 103 & 7,814 & 6,073 \\
Poland & 58 & 3,158 & 2,552 \\
United Kingdom & 55 & 15,672 & 31,888 \\
Japan & 48 & 4,730 & 5,774 \\
India & 45 & 3,623 & 3,173 \\
Spain & 45 & 3,485 & 9,313 \\
Turkey & 44 & 2,012 & 1,130 \\
Germany & 43 & 3,352 & 5,747 \\
Chile & 34 & 962 & 420 \\
Korea & 33 & 2,691 & 1,954 \\
Croatia & 31 & 1,531 & 1,312 \\
Mexico & 31 & 1,386 & 610 \\
Iran & 28 & 1,013 & 710 \\
Italy & 26 & 1,351 & 2,422 \\
Switzerland & 25 & 1,907 & 3,593 \\
Romania & 22 & 1,059 & 527 \\
Canada & 21 & 772 & 1,476 \\
Czech Republic & 20 & 1,103 & 762 \\
Argentina & 19 & 622 & 650 \\
Egypt & 19 & 966 & 1,307 \\
Serbia & 19 & 1,061 & 786 \\
South Africa & 17 & 576 & 311 \\
Colombia & 16 & 496 & 155 \\
China & 15 & 1,792 & 762 \\
Australia & 13 & 447 & 678 \\
France & 8 & 395 & 459 \\
\hline & & & \\
\hline
\end{tabular}

benefit from subsidies paid by government agencies (Emerging Infectious Diseases), nonprofit foundations (eLife), or scholarly societies (Journal of Economic Perspectives). Some journals may initially be free or inexpensive, in hopes of building up a reputation and later raising prices.

To investigate the relationship between article processing charges and journal prestige, we collected pricing information on 985 open access journals from 422 different publishers as of January 2012. To provide an overview of these data, Figure 3 shows the 2010 Article Influence scores and 2012 article processing charges for the JCRlisted open access journals.

Figure 4 compares the distribution of Article Influence scores for the open access journals with the distribution for non-open-access journals. The mean Article Influence score for all open access journals in 2010 is 0.737 . The mean Article Influence score in 2010 for non-open access journals is 0.776 . These means are not significantly different (Mann-Whitney $p$ value $=.2198$ ).

Figure 5 shows a histogram of the article processing charges levied by open access journals. The modal cost is zero, highlighting the large number of free open access journals in the data 


\section{FIGURE 3}

Article Influence Score Versus Article Processing Charges

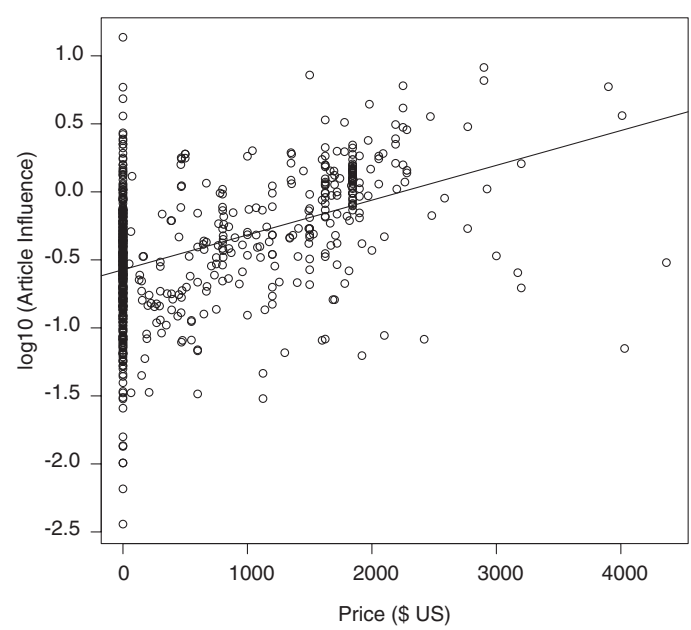

Notes: Only JCR-listed journals are included in this graph. The Article Influence scores are log transformed. The linear regression line indicates that more prestigious journals tend to have higher article processing charges.

\section{FIGURE 4}

Article Influence Distributions for Open Access Journals (top) and Non-Open-Access Journals (bottom)
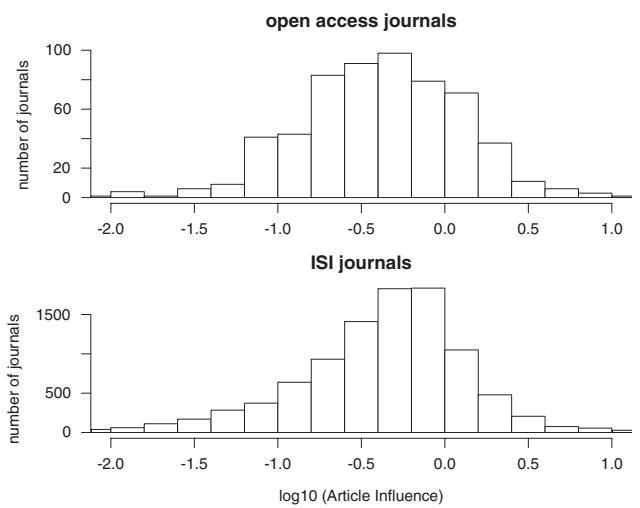

Note: The Article Influence scores are log (base 10) transformed.

set. Another prominent peak just below $\$ 2,000$ indicates a common price point for many journals that require article processing charges.

For some applications it may be desirable to quantify the cost effectiveness of open access venues using one single number. We do this
FIGURE 5

Article Processing Charges for Open Access

Journals in 2012

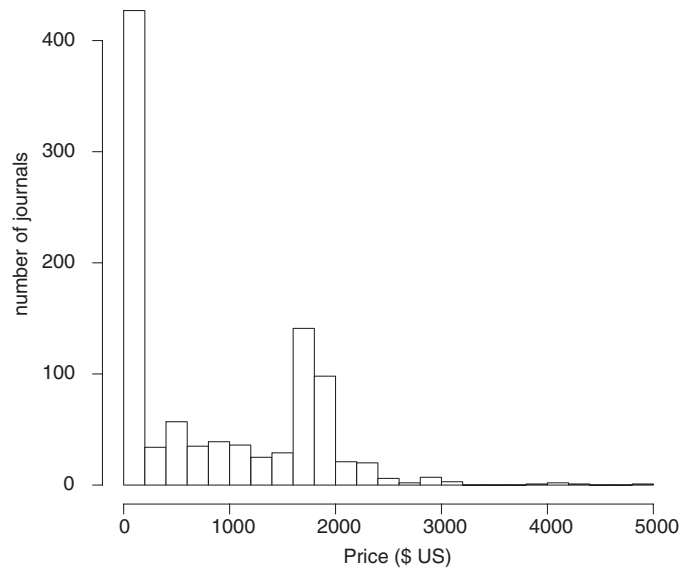

by looking at the ratio of Article Influence to article processing charges. We define the cost effectiveness of a journal as (1000* Article Influence/article processing charges). We provide cost effectiveness values for the major open access journals, and within each discipline we list open access publications ranked from the most to the least cost effective. We are able to compute Article Influence scores only for those journals listed in Thomson-Reuters' JCR. While the JCR includes over 10,000 total publications and more than 1,000 open access publications in $2011,{ }^{4}$ some newer open access journals and many lesser-known ones are not included in this list. We provide partial information for these journals, including ISSN number and article processing charges where possible, at http://www. eigenfactor.org/openaccess/nonISI.php. Some of these journals may represent good value as well, though potential authors should think carefully about the prestige and readership to be gained from publishing in journals not included in the JCR.

Open access journals offer several different pricing models. In our data set, there were 480 journals that charge a fixed fee per article. Table 4 lists the top 10 of these ranked by cost effectiveness. An additional 357 journals charge no article processing charges whatsoever; we refer to these

4. Early on, Wouter Gerritsma compiled a useful list of the open access journals indexed in the Thomson-Reuters Journal Citation Reports (Gerritsma 2011). 
TABLE 4

Top 10 Author-Pay Open Access Journals Ordered by Cost Effectiveness (CE), i.e., $1,000 *$ Article Influence Score Divided by Price

\begin{tabular}{lrlr}
\hline Journal & AI & Price & CE \\
\hline $\begin{array}{l}\text { 1. Publication of the } \\
\text { Astronomical Society of }\end{array}$ & 1.302 & $\$ 73$ & 17.841 \\
$\quad \begin{array}{l}\text { Japan } \\
\text { 2. Journal of Physiology and }\end{array}$ & 0.510 & $\$ 64$ & 7.976 \\
$\quad \begin{array}{l}\text { Pharmacology } \\
\text { 3. Asian Pacific Journal of }\end{array}$ & 0.296 & $\$ 50$ & 5.918 \\
$\quad$ Cancer Prevention & & & \\
4. Oceanography & 1.898 & $\$ 500$ & 3.795 \\
5. DNA Research & 1.897 & $\$ 500$ & 3.793 \\
6. Molecular Medicine & 1.769 & $\$ 500$ & 3.538 \\
7. PLoS Biology & 8.211 & $\$ 2,900$ & 2.831 \\
8. PLoS Genetics & 6.027 & $\$ 2,250$ & 2.679 \\
9. PLoS Medicine & 6.580 & $\$ 2,900$ & 2.269 \\
10. Evolutionary & 4.408 & $\$ 1,980$ & 2.226 \\
$\quad$ Bioinformatics & & & \\
\hline
\end{tabular}

Notes: AI is the Article Influence score. This list includes only JCR-listed open access journals that charge by the article, rather than by the page.

\section{TABLE 5}

Top 10 Free Open Access Journals Ordered by Article Influence (AI) Score

\begin{tabular}{|c|c|c|}
\hline Journal & Category & AI \\
\hline $\begin{array}{l}\text { 1. Living Reviews in } \\
\text { Relativity }\end{array}$ & High Energy Physics & 13.691 \\
\hline $\begin{array}{l}\text { 2. Journal of Economic } \\
\text { Perspectives }\end{array}$ & Economics & 5.880 \\
\hline 3. Aldrichimica Acta & Physics & 4.840 \\
\hline $\begin{array}{l}\text { 4. Bulletin of the } \\
\text { American } \\
\text { Mathematical Society }\end{array}$ & Mathematics & 3.611 \\
\hline $\begin{array}{l}\text { 5. Bulletin of the } \\
\text { American Museum of } \\
\text { Natural History }\end{array}$ & Ecology \& Evolution & 2.716 \\
\hline $\begin{array}{l}\text { 6. European Cells \& } \\
\text { Materials }\end{array}$ & Pharmacology & 2.638 \\
\hline $\begin{array}{l}\text { 7. Journal of Machine } \\
\text { Learning Research }\end{array}$ & Information Theory & 2.448 \\
\hline $\begin{array}{l}\text { 8. Bulletin of the World } \\
\text { Health Organization }\end{array}$ & Medicine & 2.375 \\
\hline $\begin{array}{l}\text { 9. Emerging Infectious } \\
\text { Diseases }\end{array}$ & Infectious Diseases & 2.240 \\
\hline 10. Bayesian Analysis & Prob \& Stats & 2.237 \\
\hline
\end{tabular}

as free journals. Table 5 lists the top 10 free journals ranked by Article Influence score. Finally, 148 journals charge by the page rather than by the article. For these journals, we multiplied the price per page by an article length of 15 pages to determine the article processing charges used in our analysis.

\section{CODA}

In this article, we develop a tool to help authors comparison shop among alternative open access venues. In general, authors should prefer journals with higher article influence scores and lower article processing charges. A separate question which we have not treated in detail here is that of how universities or funding agencies should subsidize open access publishing. In discussion of subscription-based publishing, Shieber (2009) draws the analogy between academic publishing and medical care. In both cases, consumers do not pay directly for what they consume and thus do not respond to price incentives (Shieber 2009). Shieber acknowledges, but largely dismisses, the potential for a similar problem with subsidized article processing charges. Our view is that full subsidies of article processing charges will create the same problems that arise under subscription-based publishing. We believe that it would be wiser for funders to support open access in ways that encourage price competition among open access publishers. A way to ensure that authors remain sensitive to price differences would be for funders to bear only a fraction of the cost beyond some low threshold (e.g., \$500). In economic terms, we want the price elasticity of demand to remain high. Of course, university administrators should be attentive to quality as well as price. Subsidizing publication in lowquality, low-prestige venues is not likely to be in a university's best interest.

\section{REFERENCES}

Attema, A. E., W. Brouwer, and J. Van Exel. "Your Right Arm for a Publication in AER?" Economic Inquiry, 52(1), 2014, 495-502.

Beall, J. "Predatory Publishers Are Corrupting Open Access." Nature, 489, 2012, 179.

- Scholarly Open Access. 2014. Accessed June 9, 2014. http://scholarlyoa.com/2012/12/06/bealls-list-ofpredatory-publishers-2013/.

Bergstrom, C. T., and T. C. Bergstrom. "The Costs and Benefits of Library Site Licenses to Academic Journals." Proceedings of the National Academy of Sciences of the United States of America, 101, 2004a, 897-902. . "The Economics of Ecology Journals." Frontiers in Ecology and the Environment, 4, 2006, 488-95.

Bergstrom, T. C., and C. T. Bergstrom. "Can "Author Pays' Journals Compete with 'Reader Pays'?" Nature, 2004b. Web Focus on Open Access Publishing. http:// www.nature.com/nature/focus/accessdebate/22.html.

Bergstrom T. C., and P. McAfee. Journal Cost-Effectiveness. 2013. Accessed June 9, 2014. http://journal prices.com/.

Björk, B. C., P. Welling, M. Laakso, P. Majlender, T. Hedlund, and G. Gudnason. "Open Access to the Scientific Journal Literature: Situation 2009." PLoS ONE, 5(6), 2010, e11273. 
Caveleri, P., M. Keren, G. Ramello, and V. Valli. "Publishing an E-journal on a Shoe String: Is It a Sustainable Project?" Economic Analysis and Policy, 39(1), 2009, 89-101.

Conley, J., and M. Wooders. "But What Have You Done for Me Lately? Commercial Publishing, Scholarly Communication, and Open-Access." Economic Analysis and Policy, 39(1), 2009, 71-89.

Dallmeier-Tiessen, S., R. Darby, B. Goerner, J. Hyppoelae, P. Igo-Kemenes, D. Kahn, S. Lambert, A. Lengenfelder, C. Leonard, S. Mele, M. Nowicka, P. Polydoratou, D. Ross, S. Ruiz-Perez, R. Schimmer, M. Swaisland, and W. van der Stelt. "Highlights from the SOAP Project Survey. What Scientists Think About Open Access Publishing." arXiv preprint arXiv:1101.5260, 2011.

Gerritsma, W. WoW! Wouter on the Web. 2011. Accessed June 9, 2014. http://wowter.net/2011/01/06/the-impactfactor-of-open-access-journals/.

Harnad, S. "The Green Road to Open Access: A Leveraged Transition," in The Culture of Periodicals from the Perspective of the Electronic Age, edited by A. Gács. Paris: L'Harmattan, 2007, 99-105.

"No-Fault Peer Review Charges: The Price of Selectivity Need Not Be Access Denied or Delayed." D-Lib Magazine, 16(7), 2010, 5

Kyrillidou, M. "ARL Statistics 2010-11." Technical Report, Association of Research Libraries, 2012.

Laakso, M., P. Welling, H. Bukvova, L. Nyman, B. C. Björk, and T. Hedlund. "The Development of Open Access Journal Publishing from 1993 to 2009." PLOS ONE, 6(6), 2011, e20961.
McCabe, M., and C. M. Snyder. "The Economics of Open-Access Journals.” SSRN Working Paper, 2010. Accessed June 9, 2014. http://ssrn.com/abstract= 914525.

Pinfield, S. "Paying for Open Access? Institutional Funding Streams and OA Publication Charges." Learned Publishing, 23, 2010, 39-52.

Rosvall, M., and C. T. Bergstrom. "Maps of Random Walks on Complex Networks Reveal Community Structure." Proceedings of the National Academy of Sciences of the United States of America, 105, 2008, 1118-23.

Seglen, P. O. "Why the Impact Factor of Journals Should Not Be Used for Evaluating Research." British Medical Journal, 314(7079), 1997, 498

Shieber, S. M. "Equity for Open-Access Journal Publishing." PLoS Biology, 7, 2009, e1000165.

Suber, P. Home page. 2014. Accessed June 9, 2014. http://legacy.earlham.edu/ peters/hometoc.htm

Wagner, A. B. "Open Access Citation Advantage: An Annotated Bibliography." Issues in Science and Technology Librarianship, 60, 2010.

West, J. D., T. C. Bergstrom, and C. T. Bergstrom. "The Eigenfactor Metrics (TM): A Network Approach to Assessing Scholarly Journals." College and Research Libraries, 71, 2010, 236-44.

Willinsky, J. "The Stratified Economics of Open Access." Economics Analysis and Policy, 39, 2009, 53-70.

Young, P. "The Serials Crisis and Open Access." Technical Report, Virginia Tech, 2009. 